\title{
Related Researches on Network Marketing Outsourcing Pattern
}

\author{
Zhihong Huang, Gaopeng Zhou
}

School of Economic Management, Shaanxi Institute of Technology, Xi'an Shaanxi, 710300, China

Keywords: Network Marketing, Outsourcing Pattern, Characteristics, Influence

\begin{abstract}
With the development of network information technology and popular application on the social scope, all enterprises have taken network marketing as an important way to promote the construction and development of themselves during the progress of operation and management, which has generated certain positive influence on the modernization and development of enterprises. Therefore, at the present stage, how should enterprises give the full play of network marketing during the management, it has attracted wide attention of the society. On the basis of briefly analyzing the concept, characteristics and basic type of network marketing outsourcing pattern, this paper explores the practical application value of network marketing outsourcing pattern, with the hope of offering corresponding support for the sustainable and steady development of enterprises.
\end{abstract}

\section{Introduction}

At present stage, with the improvement of Chinese scientific and technological level and development of network information technology, E-commerce industry has gradually appeared in the society and become popular rapidly. As an emerging industry in China, it has been gradually improved under the high attention of government and related social departments, which has produced correspondingly positive influence on the socialist economy modernization construction. In the E-commerce service industry, network marketing pattern has been gradually valued by most related enterprises, which have applied that pattern to the construction of enterprises and greatly promoted the development of enterprises. Therefore, this paper studies and analyzes related problems of network marketing outsourcing pattern, which has certain practical significance.

\section{Basic Concept of Network Marketing Outsourcing Pattern}

Concept of network marketing outsourcing pattern has gradually developed and been widely transmitted on the basis of 4P marketing theory. 4P marketing theory consists of four important parts, namely product, place, promotion and price. According to the supplying unit of products, it makes deep researches based on the changes of marketing demands and adjustments. Finally, enterprises can obtain certain competitive advantage in market by implementing corresponding countermeasures [1]. However, with the deepening development of Chinese socialist market economy, competitions confronted by enterprises in the market are much fiercer. Communicating speed of related information has also been fatherly accelerated. Practical application of $4 \mathrm{P}$ theory to enterprises has been challenged to a certain extent, which cannot satisfy the enterprises' requirement of modern development. Consequently, in order to let enterprises make more comprehensive and objective analysis on the market during the actual operation and management progress, 4C theory has been put forward and properly applied to enterprises. 4C theory mainly includes four elements, respectively are cost, communication, consumer and convenience,which is one kind of marketing theory taking consumers as the subject.

In the new era, affected by information technology and E-commerce concept, emergence of network marketing has created corresponding conditions for the good application of 4C theory to enterprises, which makes scientific supplement for $4 \mathrm{C}$ and $4 \mathrm{P}$ and generates certain positive influence on the development of modern society. To apply network marketing pattern to operation, enterprises can satisfy the consuming demands of consumers to the greatest extent and offer high-quality products and services for consumers. In the future economic society, it will absolutely become the 
mainstream of enterprises' marketing, so as to promote the deepening development of enterprises' marketing work.

Concretely, outsourcing service refers to that, enterprises outsource the information technology or business procedure. As information technology, being affected by related factors, enterprises seek corresponding information technology service outwardly during the developments, which usually include operation of system and basic technological services; as the business procedure, on the basis of applying information technology, enterprises outsource related business procedure, which mainly include internal management, supply chain management and business operation, etc ${ }^{[2]}$.

Above all, under the current background of market economy, network marketing outsourcing pattern concretely refers to that, enterprises need to contract network marketing business to the team with much stronger professional abilities during the operation. On that basis, relying on internet information technology, merchants obtaining the outsourcing business will make more comprehensive analysis on the advantages of related products and the current situation of the enterprise. Finally, combined with the actual situations of the enterprises, it will make a reasonable network marketing scheme, promote the marketing quality of enterprise to be correspondingly strengthened and improved, so as to make corresponding contributions for the sustainable and healthy development of the enterprise.

\section{Major Characteristics of Network Marketing Outsourcing Pattern}

\section{Complicated Combination Mode of Network Marketing}

During the practical application progress, the network marketing method requires to be highly professional, which increases the difficulty for enterprises to choose a proper marketing mode to a certain extent. For instance, when the enterprise needs to use the third-party platform, it must make a reasonable choice of E-commerce platform by integrating the product position and target market. Under general circumstance, E-commerce platform is divided into two forms, the vertical and comprehensive one. Moreover, in the practical work, combined with the working characteristics, it can make more detailed classifications [3]. Combined with the development requirement, after completing the selection of platform, enterprises can take advantage of the analysis result of network marketing to determine the more concrete marketing methods, such as setting up online stores or publishing corresponding supply information. For network marketing, the search engine marketing is also the key. For instance, enterprises can set up corresponding paid searching based on the marketing requirement, so as to give the full play of network marketing. During the operation and management progress, enterprises need to select the marketing methods based on the economic strength, industrial characteristics and products' characteristics, further to select the most suitable marketing scheme for the development of enterprises and promote the role of network marketing to be played to the greatest extent.

\section{Difficulty of Performance Evaluation under the Network Marketing Pattern}

Under the current background of market economy, during the progress of judging and evaluating the network marketing performance, it cannot only investigate the sales index of related products, but also prevent the bad influence on the science and accuracy of the evaluation result. Therefore, during the practical work, under the circumstance of limited fund, enterprises must positively explore different marketing methods to complete corresponding performance evaluation work [4]. With the relatively wide application of network marketing in enterprises, website resolution has gradually become the key point of network marketing. Website resolution can make rational evaluations of all related data in the network marketing work, such as flow carried by the network and related transactions. Only by rationally applying the website resolution to develop performance evaluation, can it guarantee the accuracy and objectiveness of evaluations, so as to offer correct guidance for development of enterprises' related work.

\section{Variability of Network Marketing Pattern}

In current society, with further development of science and technology, concrete application form of network has also consistently and correspondingly changed. Especially under the social background of "integration of three networks", enterprises have gradually had more ways to apply 
internet to implement marketing, which has generated certain positive influence on the deepening development of enterprises' marketing work. However, because the network marketing started quite late, there are certain limitations that enterprises adapt themselves to the changes of marketing pattern. Usually, enterprise cannot rationally select the best marketing pattern by integrating with the marketing demands, which results in corresponding influence on the marketing effects. Consequently, under the social background of increasingly more network application functions, if enterprises intend to fatherly improve their marketing effects, they need to make rational analysis on the multi-typed network marketing patterns, explore advantages, disadvantages and application scope of different marketing patterns, further to combine with the practical marketing demands and select the proper network marketing pattern, so as to promote better development of enterprises.

\section{Basic Types of Network Marketing Outsourcing Pattern}

\section{Outsourcing Pattern of Enterprise's Website Construction}

Website is an important foundation for an enterprise to implement the network marketing. During the development of network marketing, it is an important way for our county's related enterprises to obtain the competitive advantages in network market by constructing a specific marketing website or set up corresponding online stores on commerce website with quite huge traffic. However, because the staff members need to possess quite high network technical abilities for the purpose of constructing enterprises' websites and online stores, website construction and maintenance need professionals. For the smooth development of network marketing, if enterprise recruit high-quality talents of related majors, it will absolutely produce quite high costs, which is bad for the healthy development of enterprise. Therefore, enterprise can choose to outsource the work to a professional team, which cannot effectively reduce the costs, but also increase the technical contents of online stores and website construction, which exerts correspondingly positive influence on the effects of network marketing work.

\section{Outsourcing Pattern of Online Promotion}

During the progress of development, Chinese enterprises have gradually intensified their attention to the network marketing and constructed more and more websites, which has produced certain positive influence on the marketing of enterprises' products and services, establishment of social image and extension of customer service channel. However, due to the establishment of numerous websites and online stores, enterprises cannot present information of themselves in front of users, which is bad for the realization of marketing effects. Therefore, in order to fatherly improve the network marketing effects, enterprises still need to positively explore the network promotion way and reinforce the exposure rate of enterprises' products by proper promotion. However, implementation of online promotion still requires the staff to possess quite high professional technical abilities. As a consequence, in order to save costs and improve the working efficiency and effects, enterprises can outsource the online promotion to more professional teams, so as to guarantee the actual quality of promotion, promote enterprises to devote more efforts to the internal construction and management, and then promote the enterprise to obtain better development.

\section{Outsourcing Pattern of Content and Management}

Promotion of website can promote the information of enterprises' products to be presented in front of consumers within a quite short time, further to obtain good marketing effects. However, such a pattern is short-termed, which not only needs a lot of fund to support, but also establish the information linkage with the potential clients of enterprises, which cannot directly transform potential clients into the real clients of enterprises. The long-term efficiency and actual influence are relatively quite poor [5]. Therefore, to guarantee the long-term efficiency of network marketing and promote the enterprise's website to occupy a quite obvious position on the publicizing page for a long time, it still needs to study the working mechanism of search engine. Combined with that, it can make proper optimization of the enterprise's website or contents of online store, guarantee the enterprise information to be absorbed by the search engine preferentially, promote the enterprise's information to present in the search engine and obtain good marketing effects. However, application of search engine technology also needs the staff to possess quite high qualities of computer major, thus 
enterprise can outsource the contents and management of the website for achieving the best marketing effects. On the basis of improving the marketing qualities, it can promote better development of the enterprise's website.

\section{Application Value of Network Marketing Outsourcing Pattern}

\section{Reducing the Application Threshold of Enterprise's Network Marketing}

Network marketing absolutely involves in related knowledge of several disciplines. Moreover, with the rapid development of network information technology, the implementation of network marketing has gradually become difficult. If enterprises do not have professional marketing talents, they cannot give the play of actual marketing effects, which will produce bad influence on the modernization construction of enterprises. However, reasonable application of the network marketing outsourcing pattern can fatherly lower the threshold for enterprises to implement the network marketing work, which can promote enterprises to outsource the network marketing to professional network marketing service team. Combined with the practical marketing demands of related products, professionals can develop reasonable marketing plans and measures, so as to guarantee technological advantages and management advantages of network marketing can be fully played, which produces correspondingly positive influence on the sustainable and healthy development of enterprises. Under the network marketing outsourcing pattern, enterprises need not to make combinations or innovations of the current business procedures, but only need to pay certain network marketing fee to professional marketing team and then obtain corresponding marketing effects. Enterprises can be promoted to devote more efforts to the management of core business, which can offer corresponding guarantee for the sustainable and healthy development of enterprises.

\section{Fatherly Reducing the Network Marketing Cost of Enterprises}

To develop concrete network marketing work, enterprises need to employ high-quality professional network marketing personnel. They also need to spend a lot of money. As some quite special marketing methods, such as search engine marketing and network advertising marketing, require enterprises to input certain human, material and financial support. Once it is not done properly, it will result in corresponding marketing risks, which is bad for enterprises to obtain marketing effects and good operation in modern society. Reasonable application of network marketing outsourcing mode can effectively cut down the marketing cost of enterprises. Enterprises do not need to set up professional marketing management departments, but they can obtain corresponding network marketing effects. Moreover, because enterprises undertaking marketing outsourcing business usually possess quite strong professional abilities, the network marketing outsourcing pattern can obtain quite good marketing effects, which is worthy of being fatherly promoted and applied.

\section{Gradually Improving the Network Marketing Efficiency}

During the progress of applying the network marketing outsourcing pattern, enterprises can cooperate with the service provider of network marketing, which cannot only save corresponding network marketing cost, but also get more professional marketing service, which has certain positive influence on the improvement $\mathrm{f}$ marketing efficiency and reinforcement of marketing effects. In the marketing pattern, outsourcing service unit of network marketing can offer high-quality services for enterprises, including formulation, enforcement, order processing and after-sales service of the marketing scheme. Enterprises only need to distribute commodities according to the orders after the marketing, so as to complete the online electronic transaction. The marketing efficiency has been obviously improved, which is good for the healthy development of enterprises.

\section{Conclusion}

In conclusion, development of market economy and dynamic changes of network marketing have brought certain opportunities for the development of enterprises' network marketing work. Meanwhile, there are corresponding challenges. Therefore, during the progress of construction, enterprises should positively explore the network marketing outsourcing pattern, improve the 
expertise and effectiveness through network marketing outsourcing, so as to offer corresponding guarantee for the sustainable and healthy development of enterprises in the modern society.

\section{References}

[1] Sun Xuewen. Researches on Innovative Network Marketing Outsourcing Pattern. Commercial Times, 2011(7):30-31.

[2] Du Rongliang, Cao Xiang. Analysis on Network Marketing Outsourcing Pattern of SMEs. Modern Business Trade Industry, 2012(23):92-93.

[3] Lei Lei. Researches on Innovative Network Marketing Outsourcing Pattern. New Course • Middle, 2013(6):146-146.

[4] Yi Fenghua. Analysis on Risks of Network Marketing Outsourcing. Journal of Hubei University of Economics: Humanity and Social Science Edition, 2011,08(10):56-57,70.

[5] Liu Lihong. Developement Trend of Chinese Network Marketing from the Mode of "Mbaobao". Value Engineering, 2013,32(5):171-172. 